\title{
Rescaling stable isotope data for standardized evaluations of food webs and species niches
}

\author{
Brian Fry*, Jean Davis
}

Australian Rivers Institute, Gold Coast Campus, Griffith University, Parklands Drive, Southport, QLD 4222, Australia

\begin{abstract}
Many human and natural events can impact aquatic populations and communities, leaving strong imprints as altered food web dynamics. Stable $\mathrm{C}$ and $\mathrm{N}$ isotopes in fish can record these altered trophic dynamics in an integrated way, and a new simple methodology is presented to extract measures of food web change from isotope measurements of fish species. Measured $\mathrm{C}$ and $\mathrm{N}$ isotope data are re-scaled as modified $Z$-scores to equalize the effects of average food inputs, then graphed in $(x, y)$ space to obtain food web shapes. Pairs of food webs are compared for shifts in Euclidean distance of isotope values for individual species and pairs of species, and these shifts are used to assess overall constancy of species niches and fish food webs. Application of the methodology shows that (1) on average, estuarine fish species are relatively fixed in their trophic niches, with only 14 to $24 \%$ variability in the niches; (2) relatively undisturbed natural fish communities often show substantially different food web structure even when the same species of fish are present; and (3) factors such as species invasions and dredging result in marked differences between food webs. Isotope evaluations of possible food web shifts should be valuable in many conservation and restoration contexts.
\end{abstract}

KEY WORDS: Carbon $\cdot$ Nitrogen $\cdot$ Isotopes $\cdot$ Food webs $\cdot$ Niches $\cdot$ Fish

\section{Resale or republication not permitted without} written consent of the publisher

\section{INTRODUCTION}

Over several decades, studies have used stable isotopes to elucidate food web structure, particularly in aquatic systems where direct observations of feeding are difficult. The isotopes have advantages of record-

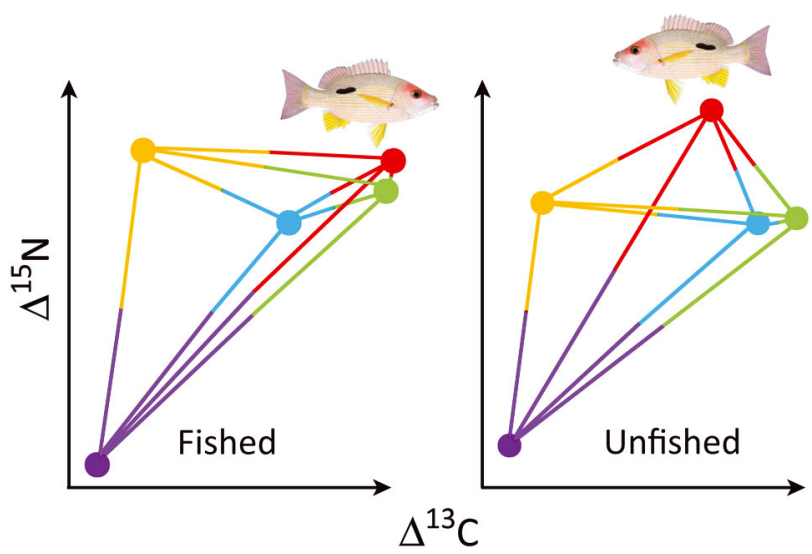

Standardized isotope diagrams of fish food webs (red dot: snapper; other dots: other fish species) in fished and unfished areas of Moreton Bay estuary, Australia.

Image: B. Fry, J. Davis

ing time-integrated, assimilated diets, although they rarely record the taxonomic basis of these diets. The carbon (C) isotope chemical marker approach is generally used to investigate organic matter sources supporting fish growth, and fish trophic level is investigated with nitrogen $(\mathrm{N})$ stable isotopes. Combined use of $\mathrm{C}$ and $\mathrm{N}$ stable isotopes has been proposed as a way to measure niche dimensionality (Bearhop et al. 2004), and routine use of isotope technology is now growing for measuring changes in food web dynamics (Layman et al. 2012, Syväranta et al. 2013).

Despite the advances in stable isotope analysis, several problems have emerged when using stable isotopes to describe feeding relationships. The most common difficulty is 'too many sources and not enough tracers', so that multiple food source combinations are possible or feasible for the same measured isotope niche data (Phillips 2012). A related 
problem is that inconspicuous food sources may be important but are frequently missed in field sampling efforts, so that additional sources are possible and 'final' food webs are always somewhat uncertain (Fry 2013a). In addition, a scale for the isotope niche dimensions is often lacking, so that evaluation of a niche as 'large' or 'small' can be subjective (Hoeinghaus \& Zeug 2008). Finally, apparent isotope niche changes can be due to changes in basal or baseline shifts in food isotope values, rather than reflecting true changes in fish feeding behaviour. Thus, several problems related to food isotope distributions can make food web interpretations difficult. These problems all stem from viewing food webs from the bottom, trying to estimate which basal plant and microbial sources are important for higher-level consumers.

Here we take an alternative top-down approach to food webs, and use isotope values of consumers to estimate food web linkages. The approach does not estimate basal source contributions, but focuses on the interactions between consumer species or functional groups. We present a standardized way to measure fish food webs after re-scaling measured isotope data into modified $Z$-scores. Use of modified $Z$-scores accounts for different baselines and food resource mixes supporting fish food webs, so that the isotope dynamics relating to fish species interactions and behavioural niches are revealed and become the object of study. Thus, the focus here is on fish species interactions rather than on the more traditional partitioning of food source contributions done with isotope tracers.

Our methodology builds on approaches developed previously (Schmidt et al. 2007, Turner et al. 2010), but with a focus here on using species rather than feeding guilds (Turner et al. 2010) as the basis for food web analysis. Example applications are given comparing estuarine food webs across salinity gradients in the USA and inside and outside 'nofishing' marine reserves in Australia. Simple rescaling steps for means and individual data are reported in detail here for the first time, and examples show that using this type of standardized rescaled data can be useful in environmental assessments of fish trophodynamics. Our approaches represent a distillation of previous methods for isotope comparisons of food webs and can be used in single studies to compare food webs as well as for comparative meta-analyses. We included a wide variety of multiple-species fish food webs in this study to ensure our recommended approaches are general and widely applicable.

\section{METHODS}

\section{Data sources}

Species averages and associated errors (standard deviations, standard errors and 95\% confidence limits) were taken from tables and figures in published studies. In most cases, the data were available only for selected species in a food web, not for all abundant species. We also used data from fish food webs that we studied previously.

Data for 3 food webs from Barataria Bay, Louisiana (USA), were taken from Fry \& Chumchal (2011). These food webs were arranged along a salinity gradient, with average salinities at the times of fish collections of 6, 9 and 17 for Fisherman's Point (FP), Manilla Village (MV) and Grande Terre (GT), respectively (Fry 2013b); salinity of full-strength seawater is 36 . Food web comparisons tested for possible differences in trophic structure at these 3 stations that represent typical low, medium and high salinity sites in the Louisiana bay systems.

Fish food webs at several fringing reef sites in eastcentral Moreton Bay, Australia, were studied previously, with fish collected over several different days at each reef in winter 2012 (Davis et al. 2014). Sites were all located in higher (>30) salinity zones of eastern Moreton Bay within $5 \mathrm{~km}$ of one another. The site at Goat Island (GI) had branching coral, and 3 sites around nearby Peel Island (PI) had respectively less (PI1, PI3) and much less coral diversity and complexity (PI7). The GI and PI sites all had commercial fishing bans but allowed recreational fishing. Four sites were located in marine reserves where no fishing was allowed (Myora, PI1, PI5 and PI6), and several comparisons were made to test food web similarity between pooled data from these reserve sites versus non-reserve sites (GI, PI2, PI3 and PI7). Comparisons were also made between the pooled reserve sites and several individual sites. Fish from these estuarine studies were generally 5 to $50 \mathrm{~cm}$ in length (Fry \& Chumchal 2011, Davis et al. 2014).

\section{Sample type and analysis}

Fish muscle tissue was used in all studies, and was analysed for $\mathrm{C}$ and $\mathrm{N}$ isotopes by elemental analyser systems linked to isotope ratio mass spectrometers (Fry 2007). Data are reported as \% deviations from the Vienna PeeDee Belemnite standard for carbon and from air nitrogen via the $\delta$ definition, where $\delta^{13} \mathrm{C}$ or $\delta^{15} \mathrm{~N}=\left[\left(R_{\mathrm{SAMPLE}} / R_{\mathrm{STANDARD}}\right)-1\right] \times 1000$, where $R=$ ${ }^{13} \mathrm{C} /{ }^{12} \mathrm{C}$ or ${ }^{15} \mathrm{~N} /{ }^{14} \mathrm{~N}$. 


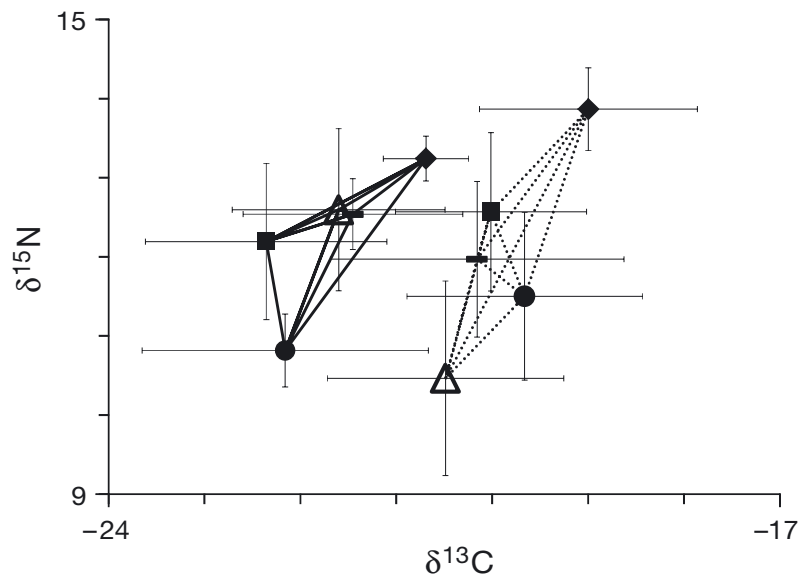

Fig. 1. Measured isotope values for 2 food webs of Barataria Bay, Louisiana. Each food web has the same 5 fish species. Lines connect species in food webs (solid lines: Manilla Village, in the fresher, upper bay; dotted lines: Grande Terre, in the more saline, lower bay). Lines also represent axes of potential niche interaction between fish species. Points are mean values for species and error bars are $95 \%$ confidence limits. Open triangles = gulf menhaden Brevoortia patronus, closed circles = ladyfish Elops saurus, diamonds = hardhead catfish Ariopsis felis, squares = spot Leiostomus xanthurus, bars = Atlantic croaker Micropogonias undulatus

\section{Steps in rescaling and comparisons}

The detailed steps of rescaling data are introduced below, but the overall process is designed to overlay food webs and species in 2D isotope graphs. For example, original data for 2 of the Barataria food webs (Fig. 1) seem to indicate separate food webs, but after rescaling, the 2 food webs can be overlaid and prove fairly similar (Fig. 2). Details of how to do the rescaling and how to estimate similarity are given in 4 steps below, and sample calculations for the rescaling process are given in Supplement 1 (www. int-res.com/articles/suppl/m528p007_supp.pdf).

Most of this study and Supplement 1 starts with species averages rather than individual-level data. We used averages rather than individual data in this study because of simplicity of calculation and because the published food web studies that we used in calibrations reported only means without individual data. Our average-based methods thus do not employ multivariate techniques such as cluster analysis that require individual-level data to identify similarities and differences between grouped individual data. Where individual-level data are available, it can be rescaled (see Supplement 2) to give the same results as we provide using species averages. Supplement 2 shows that some non-intuitive steps can apply when rescaling individual data, but future studies will likely use individual-level data, and may

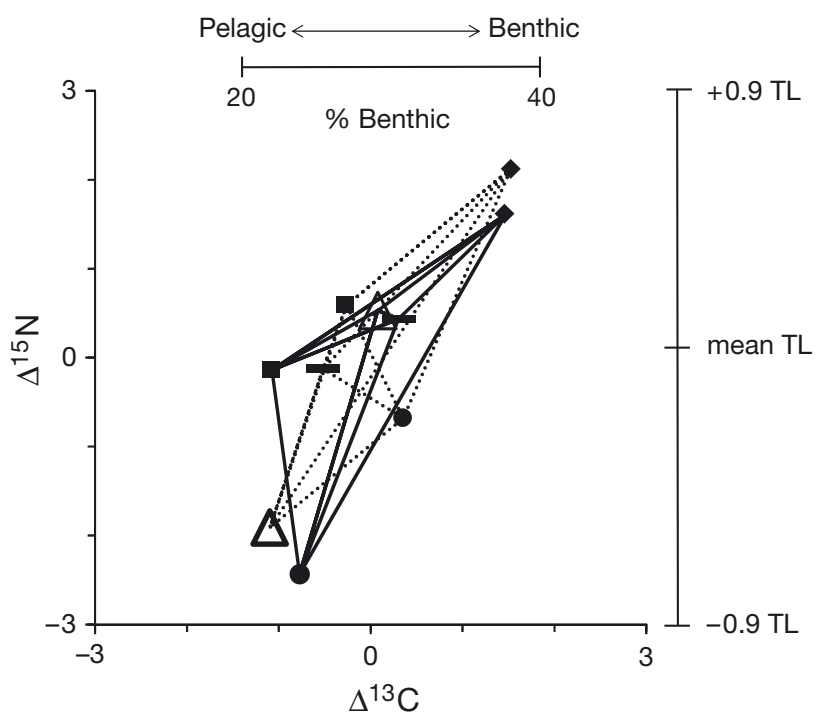

Fig. 2. Rescaled isotope values for the 2 food webs of Fig. 1; confidence intervals have been omitted for clarity. Menhaden (open triangles) show the most change between the 2 food webs, with ladyfish (closed circles) also showing relatively strong trophic shifts in the 2 food webs. Rescaled fish data usually fall along a gradient of pelagic and benthic feeding strategies $\left(\Delta^{13} \mathrm{C}\right)$ and trophic level $\left(\Delta^{15} \mathrm{~N}\right)$; the particular scaling values shown here of $20-40 \%$ benthic for $\Delta^{13} \mathrm{C}$ and $3 \%=0.9$ trophic level (TL) for $\Delta^{15} \mathrm{~N}$ are based on previous studies of Louisiana estuary fish (Fry \& Chumchal 2012, Fry 2013b). Dotted lines connect species in the Manilla Village food web, solid lines connect species in the Grande Terre food web

choose to work with multivariate programs (see Supplement 3) to assess many of the similarities we estimated here with our averages-based approach. We used the following 4 steps for rescaling and estimating similarity: (1) calculating $Z$-scores from the data, (2) calculating distances and errors for 2 comparative methods, (3) calculating \% similarity for species or food webs and (4) testing for significance.

\section{Step 1: Calculating $Z$-scores}

Modified Z-scores were calculated from species averages and standard deviations (SD), for example as:

$Z_{\text {modified species }}=\mathrm{SD}_{\text {rescaled }} \times Z$-score $=\mathrm{SD}_{\text {rescaled }} \times$

(species mean - community mean) $/ \mathrm{SD}_{\text {community }}$

The usual $Z$-scores lack the $\mathrm{SD}_{\text {rescaled }}$ term and give differences among data in standard deviation units. Multiplication of the $Z$-score by $\mathrm{SD}_{\text {rescaled }}$ puts the data back into \%o units of the original measurements, when $\mathrm{SD}_{\text {rescaled }}$ is an average \%o value chosen by the investigator to represent a typical value for the communities studied. The $\mathrm{SD}_{\text {rescaled }}$ values used here were $1.0 \%$ for 
$\delta^{13} \mathrm{C}$ and $1.5 \%$ for $\delta^{15} \mathrm{~N}$, with the 1.0 and $1.5 \%$ values representing average $\mathrm{SD}$ values for the wide range of fish communities considered in this study. Confidence limits for the species were similarly re-scaled by multiplying measured confidence intervals by $(1.0 \%$ o $\left.\mathrm{SD}_{\text {community }}\right)$ for $\delta^{13} \mathrm{C}$ and by $\left(1.5 \% / \mathrm{SD}_{\text {community }}\right)$ for $\delta^{15} \mathrm{~N}$. Note that although these 1 and $1.5 \%$ multipliers applied generally across this study, they can also be reset as needed to reflect the average standard deviations in food webs being compared. A simpler default set of multipliers is to use $1 \%$ for all $Z$-scores, so that the rescaled data have units $1 \%=1$ average standard deviation. In these rescaling steps, any multipliers should be applied to errors as well as averages, as detailed in Supplement 1. For fish communities, rescaled $\Delta^{13} \mathrm{C}$ usually indicates relative reliance on benthic and pelagic foods (Vander Zanden \& Rasmussen 1999). But the differences between benthic and pelagic end members are not constant across systems, so that \% benthic calculations (20-40\% in the Fig. 2 example) typically use system-specific values determined in each food web study (Mallela \& Harrod 2008, Vander Zanden et al. 2011). The $\Delta^{15} \mathrm{~N}$ scaling of trophic level is also subject to revision for different fish communities, with values of $2.2-3.4 \%$ typically used to indicate a difference of 1 trophic level (McCutchan et al. 2003, Fry \& Chumchal 2012).

Step 2: Distance and error calculations for 2 methods

We used rescaled species-average isotope data to make comparisons between paired food webs, with 2 methods: (1) a same-species point comparison method (Method 1) and (2) a mixed-species line comparison method (Method 2). Both methods use distances between points as the simplest way to estimate shape differences (Osada et al. 2002). Philosophically, single-species Method 1 isolates change pertaining to individual species, while mixed-species Method 2 considers these same species as nodes in a multipleconnection interaction web.

The 2 methods can also be illustrated with reference to Fig. 2. Method 1 uses the difference between 2 same-species points such as the diamonds representing hardhead catfish Ariopsis felis in the 2 food webs (Fig. 2). These 2 points are close to one another and will score as highly similar by distance-based measurements. This type of same-species comparison is possible for all 5 species in the food web of Fig. 2. In Method 2, lines between species are compared, for instance the dotted and solid lines connecting diamonds (hardhead catfish) and squares (spot Leiostomus xan- thurus) can be compared for the 2 food webs (Fig. 2). These lines are similar in length and orientation and will score as highly similar. Between-species comparisons are possible for all 10 lines connecting species in the Fig. 2 food webs. Overall, Method 1 gives only as many similarity estimates as there are species in the paired comparisons (5 same-species comparisons for Fig. 2), while Method 2 is more data-rich (10 betweenspecies comparisons for the lines of Fig. 2). The methods are both based on paired comparisons and can be used to evaluate both similarity of entire food webs and similarity of species niches in different food webs. However, the 2 methods yielded similar though somewhat different answers, so that we present details of calculations for both methods.

Method 1 used distances between same-species points to judge similarity. Distances between points were calculated from the Pythagorean theorem, so that for 2 points $\left(x_{1}, y_{1}\right)$ and $\left(x_{2}, y_{2}\right)$ the distance $(D)$ was

$$
D=\operatorname{sqrt}\left[\left(x_{1}-x_{2}\right)^{2}+\left(y_{1}-y_{2}\right)^{2}\right]
$$

The error $(E)$ for this distance was calculated from the errors associated with the points according to the formula for determining errors for distances measured in Euclidean space:

$$
\begin{aligned}
E=D^{-1} \cdot \operatorname{sqrt} & \left\{\left(x_{1}-x_{2}\right)^{2} \cdot\left[\left(E_{x 1}\right)^{2}+\left(E_{x 2}^{2}\right)\right]\right. \\
& \left.+\left(y_{1}-y_{2}\right)^{2} \cdot\left[\left(E_{y 1}\right)^{2}+\left(E_{y 2}\right)^{2}\right]\right\}
\end{aligned}
$$

Method 2 compares between-species lines in 2D food web diagrams. We considered lines connecting species in $2 \mathrm{D}$ isotope plots to be vectors, and our detailed calculations compared vector tips in 2 food webs for the between-species comparisons. For example, if species A and B in food web 1 had respective isotope values of $(1,1)$ and $(2,2)$, the vector tip at $\mathrm{B}\left(x_{\mathrm{v} 1}, y_{\mathrm{v} 1}\right)$ would have a $(1,1)$ value when recalculated to $\mathrm{A}$ as the local $(0,0)$ value, and if species A and $B$ in food web 2 had respective isotope values of $(-3,-3)$ and $(-4,-4)$, then the vector tip at $\mathrm{B}\left(x_{\mathrm{v} 2}, y_{\mathrm{v} 2}\right)$ would have a $(-1,-1)$ value when recalculated relative to $A$ as the local $(0,0)$. The information needed to represent the differences between the 2 lines is given as the distances between these 'tip of the vector' points, $\left(x_{\mathrm{v} 1}, y_{\mathrm{v} 1}\right)$ for line 1 and $\left(x_{\mathrm{v} 2}, y_{\mathrm{v} 2}\right)$ for line 2, along with the propagated errors associated with these 2 points. In essence, we converted a comparison of lines into a comparison of points in this method, with the 4 points involved in the start and ends of the vectors collapsed into 2 points that are tips of vectors. Note that the choice of which points start and end the vector is arbitrary (vectors could be from A to B or B to $\mathrm{A})$, but once the vector orientation is chosen in food web 1, the corresponding vector in the second 
food web should have the same species start and end. That is, if the vector in food web 1 is from species A to species B, then the vector in food web 2 should also be from species A to species B.

The distance between the vector tips was calculated from the Pythagorean theorem,

$$
D=\operatorname{sqrt}\left[\left(x_{\mathrm{v} 1}-x_{\mathrm{v} 2}\right)^{2}+\left(y_{\mathrm{v} 1}-y_{\mathrm{v} 2}\right)^{2}\right]
$$

Estimating errors for this distance proceeded in 2 steps. First, propagated errors for each of the 'tip of the vector' points were calculated from the errors associated with the species points at the start and end of the vectors. Errors associated with the start and end points in food web 1 were respectively ( $E_{1 \text { start } X \text {, }}$ $\left.E_{1 \text { start } Y}\right)$ and $\left(E_{1 \text { end } X}, E_{1 \text { end } Y}\right)$, and errors associated with the start and end points in food web 2 were similarly $\left(E_{2 \text { start } X}, E_{2 \text { start } Y}\right)$ and $\left(E_{2 \text { end } X}, E_{2 \text { end } Y}\right)$. The propagated errors $\left(E_{X \mathrm{v} 1}, E_{Y \mathrm{v} 1}\right)$ for the 'tip of the vector point' $\left(X_{\mathrm{v} 1}\right.$, $\left.Y_{\mathrm{v} 1}\right)$ in food web 1 were:

$$
\text { and } \begin{aligned}
E_{X \mathrm{v} 1} & =\operatorname{sqrt}\left[\left(E_{X 1 \text { start }}\right)^{2}+\left(E_{X 1 \text { end }}\right)^{2}\right] \\
E_{Y v 1} & =\operatorname{sqrt}\left[\left(E_{Y 1 \text { start }}\right)^{2}+\left(E_{Y 1 \text { end }}\right)^{2}\right]
\end{aligned}
$$

Similarly the propagated errors $\left(E_{X \mathrm{v} 2}, E_{Y \mathrm{v} 2}\right)$ for the 'tip of the vector point' $\left(x_{\mathrm{v} 2}, y_{\mathrm{v} 2}\right)$ in food web 2 were:

$$
\text { and } \begin{aligned}
E_{X \mathrm{v} 2} & =\operatorname{sqrt}\left[\left(E_{X 2 \text { start }}\right)^{2}+\left(E_{X 2 \text { end }}\right)^{2}\right] \\
E_{Y \mathrm{v} 2} & \left.=\operatorname{sqrt}\left[\left(E_{Y 2 \text { start }}\right)^{2}+\left(E_{Y 2 \text { end }}\right)^{2}\right)\right]
\end{aligned}
$$

Using these propagated errors, the error for the distance between these 'tip of the vector' points is:

$$
\begin{aligned}
E= & D^{-1} \cdot \operatorname{sqrt}\left\{\left(x_{\mathrm{v} 1}-x_{\mathrm{v} 2}\right)^{2} \cdot\left[\left(E_{X \mathrm{v} 1}\right)^{2}+\left(E_{X \mathrm{v} 2}\right)^{2}\right]\right. \\
& \left.\left.+\left(y_{\mathrm{v} 1}-y_{\mathrm{v} 2}\right)^{2} \cdot\left[\left(E_{Y \mathrm{v} 1}\right)^{2}+\left(E_{Y \mathrm{v} 2}\right)^{2}\right)\right]\right\}
\end{aligned}
$$

In summary, both the within-species Method 1 and between-species Method 2 calculated Euclidean distances $(D)$ and errors $(E)$ from rescaled data. These terms could be united into a single distance/error $(D / E)$ parameter that is also a signal-tonoise (S:N) ratio defined in this study using $95 \%$ confidence limits as errors, so that $\mathrm{S}: \mathrm{N}=$ Euclidean distance $/ 95 \%$ CL. S:N ratio values near 0 indicated great similarity, but larger values indicated increasing dissimilarity. To convert the $\mathrm{S}: \mathrm{N}$ ratios into simpler estimates of similarity on a scale of 0 to $100 \%$, we developed an empirical calibration between \% similarity and S:N ratios using a broad range of isotope studies of fish food webs. Calculations indicated that $\mathrm{S}: \mathrm{N}$ ratios $>1$ indicated large differences that were statistically significant at approximately $\mathrm{p}=0.05$ or better (Supplement 4).

\section{Step 3: Calibrating \% similarity with S:N ratios}

We used data from several calibration studies that each had multiple (5 to 10) fish species or groups sampled at least twice, allowing 1 or more pairwise comparisons of species shifts or group shifts. The studies included (1) 4 east-coast African estuary food webs where fish functional groups were sampled before and after flooding (Abrantes et al. 2013), (2) 3 estuarine food webs from turbid, lower salinity Louisiana systems (Fry \& Chumchal 2011), (3) 6 estuarine food webs from higher-salinity and clearerwater Australian systems (Davis et al. 2014), (4) 3 deep-sea food webs from the eastern, central and western Tasman Sea (Flynn \& Kloser 2012), (5) seasonal studies of the deep-sea fish food webs in the Mediterranean Sea (Papiol et al. 2013), (6) river food webs at dredged versus undredged sites (Freedman et al. 2013) and (7) 2 freshwater pond food webs representing a control food web and a food web after addition of an invasive fish species (Britton et al. 2010). These diverse food webs showed a wide range in average S:N ratio estimates, and in each study, we also counted the proportions of observations that had $\mathrm{S}: \mathrm{N}<1$ and $>1$ in food web comparisons made over time or space. In these calculations, if 2 food webs had 5 species in common but only 1 species had S:N $>1$, there was only a 0.2 or $20 \%$ difference in the food webs, and we counted them $80 \%$ similar. We counted these proportions across all food webs in each study and compared this to the average S:N

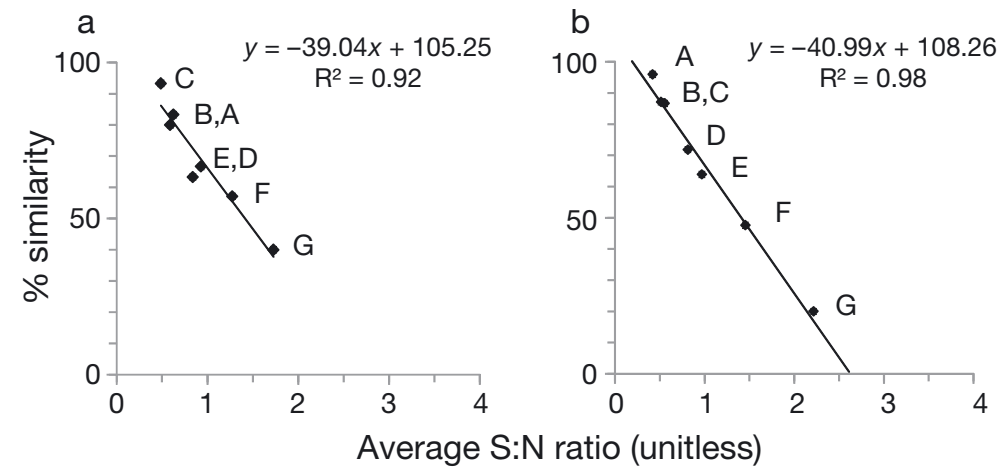

Fig. 3. Calibrations for 2 methods of calculating similarities across fish food webs based on S:N ratio measurements of rescaled data: (a) withinspecies Method 1, (b) between-species Method 2. Data are averages from 7 studies, $A-G$, as follows: $A=4$ African floodplain estuaries, pre- vs. post-flood comparisons of fish functional groups (Abrantes et al. 2013); $\mathrm{B}=$ Moreton Bay (Australia) estuary, several sites (this study); $\mathrm{C}=$ Louisiana (USA) estuaries, 3 sites (Fry \& Chumchal 2011, this study); D = deep Tasman Sea between Australia and New Zealand, 3 sites (Flynn \& Kloser 2012); E = deep Mediterranean Sea, 4 seasons (Papiol et al. 2013); $\mathrm{F}=\mathrm{US}$ dredged vs. undredged river, aggregated sites (Freedman et al. 2013); $\mathrm{G}$ = freshwater English ponds, control pond vs. impact pond with an invasive species (Britton et al. 2010) 
ratio for the food webs. This meant that we had 2 types of data for $\mathrm{S}: \mathrm{N}$ ratios in each study, viz. the average $\mathrm{S}: \mathrm{N}$ values and the proportional similarity of the whole food web based on the $S: N$ values above and below 1 . We expected these 2 estimates of $\mathrm{S}: \mathrm{N}$ to be similar, and regressions across the calibration studies fit this expectation, with strong $\left(\mathrm{r}^{2}>0.9\right)$ linear fits resulting between proportionally measured $\%$ similarity and continuously measured $\mathrm{S}: \mathrm{N}$ values (Fig. 3).

The regressions of Fig. 3 allowed us to convert our measured S:N data into \% similarity estimates for Methods 1 and 2. Thus, if point-based (Method 1) S:N values averaged $0.8 \pm 0.3 \%$ o (mean $\pm 95 \% \mathrm{CL}$ ) in a comparison between 2 food webs, the food web similarity using the equation from the point-based method shown in Fig. 3a was $66 \pm 15 \%$. Continuing this example, if a line-based (Method 2) comparison of the food webs gave these same $\mathrm{S}: \mathrm{N}$ values of $0.8 \pm$ $0.3 \%$ (mean $\pm 95 \% \mathrm{CL}$ ), the food web similarity using the equation from the line-based method shown in Fig. 3b was $75 \pm 12 \%$. The similarity equations of Fig. 3 are based on a diverse set of food webs, and should be applicable in future comparative studies of isotope food webs. A caveat is that the equations will need adjustment to gradually approach 0 at high $\mathrm{S}: \mathrm{N}>2.6$. We did not encounter such cases of average $\mathrm{S}: \mathrm{N}>2.6$ in this overview study, but such cases could be scored as approximately $0 \%$ similar.

Step 4: Evaluating statistical significance with bimodal S:N ratios

Similarity comparisons for species in paired food webs or at different sites showed bimodal distributions, with some species quite similar in all circumstances but other species showing much more variation in time or space. Because of this split into relatively constant and relatively variable species, our analysis of significant differences focused on the variable species, and we considered that differences were significant when a substantial fraction of the fish species in food webs showed $\mathrm{S}: \mathrm{N}>1$. The regressions of Fig. 3 indicate that average similarities less than 66 or $67 \%$ correspond to S:N > 1 and statistical comparisons summarized in Supplement 4 indicated that $\mathrm{S}: \mathrm{N}$ values $>1$ corresponded approximately to $\mathrm{p}<0.05$. Using these values, we estimated that significant differences near $\mathrm{p}=0.05$ existed between paired food webs or for a species across sites when more than $1 / 3$ of the observations in Method 1 or Method 2 evaluations showed $\mathrm{S}: \mathrm{N} \geq 1$. In cases where more than half the observations showed S:N $\geq 1$, a stronger level of significance was indicated with $\mathrm{p}<0.05$.

\section{RESULTS}

The 2 methods gave similar average results for sites and species in the USA and in Australian estuarine food webs (Fig. 4). For both the USA and Australian food webs, 5 species were involved, but there were 3 sites in the USA, compared to 4 individual sites and 2 aggregated sites in Australia. Site comparisons are presented pairwise in Fig. 4 a, and species comparisons made across the paired sites of Fig. 4a are shown in Fig. 4b.

The 2 methods gave broadly similar average results, although averages in the point-based singlespecies Method 1 were almost always lower and errors always higher than for the line-based mixedspecies Method 2. This difference in errors is mostly due to the larger number of observations involved for lines than for points; for example, data for 10 lines contributed to the Method 2 averages for the 5 species food webs of Fig. 4, but only data for 5 species contributed to the Method 1 averages. The mixedspecies Method 2 estimates also are generally better buffered because of these higher numbers of observations, and in the comparisons shown in Fig. 4, the Method 2 results had smaller ranges of values than the Method 1 results. These better-buffered values of Method 2 also reflect the basic connectedness assumed between species in this method, with connectedness further averaging the data and contributing to smaller errors.

Significance testing with $\mathrm{S}: \mathrm{N}$ ratios showed that the 2 methods usually gave similar results in the 7 comparisons where significant differences were detected, although the same-species method showed stronger differences in 3 cases (Fig. 4; R vs. GI, painted sweetlips Diagramma labiosum, Moses perch Lutjanus russelli). The stronger differences likely relate to reduced propagated errors in Method 1 that relies on 2 points instead of the 4 points involved in Method 2 calculations. These initial observations suggest that Method 1 more easily detects significant differences between sites and species, while Method 2 is the more conservative method for assessing these differences. In summary, we generally relied more on between-species Method 2 in our species and site evaluations because this method conceptually emphasized linkages among species, had smaller errors in \% similarity estimates (Fig. 4) and gave more con- 
Fig. 4. Example pairwise trophic comparisons for (a) sites and (b) species using the 2 methods. Values are means $\pm 95 \%$ confidence limits, ${ }^{*} p=0.05,{ }^{* *} p<0.05$ detected with signal:noise (S:N) ratios (see 'Methods'). Bars grouped on the left are from Barataria Bay, Louisiana (USA), and those grouped on the right are from Moreton Bay, Australia. Site comparisons in Louisiana are between sites in upper (FP), mid (MV) and lower (GT) bay and show food web changes along a salinity gradient. The site comparisons in Australia all involve comparisons to sites in a recently declared no-fishing marine reserve ('R' sites), with various sites (GI, PI3, PI1, PI7, aggregated non-reserve sites $=$ 'NON') differing as shown from the reserve. Scientific names for Louisiana fish (left) are given in Fig. 1, scientific names for Australian fish (right) are painted sweetlips Diagramma labiosum, Moses perch Lutjanus russelli, wrasse Pseudolabrus guentheri, yellowfin bream Acanthopagrus australis, rabbitfish Siganus fuscescens

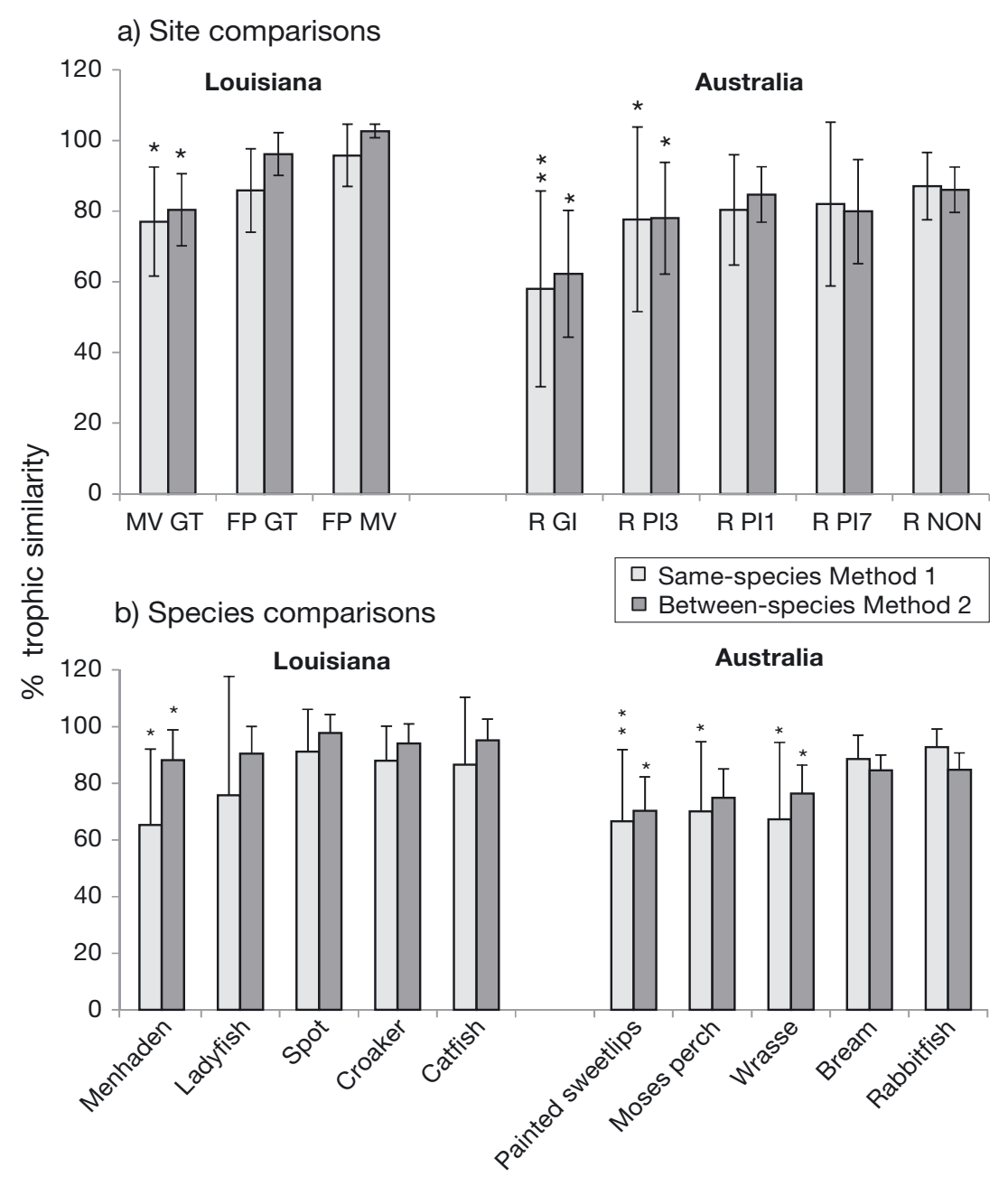

servative estimates of food web differences using S:N ratios. However, Method 1 remains useful if species are more separated than linked in food webs, and because Method 1 results give a more liberal view of differences between species and food webs.

The pairwise comparison of food webs showed average similarities that ranged from nearly identical (FP vs. MV food webs in the USA, almost $100 \%$ similar) to quite dissimilar (R vs. GI sites in Australia, only $50 \%$ similar). Of the 8 food web pairs shown in Fig. 4a, 5 pairs were considered not significantly different, but both methods agreed that there were significant differences in the food webs of the other 3 pairs (MV vs. GT in the USA, R vs. GI and $\mathrm{R}$ vs. PI3 in Australia). The underlying data used to make these food web comparisons were collected for fish species, and several species showed significant differences across the food web pairs of Fig. $4 \mathrm{a}$. Thus, in the USA, the gulf menhaden Brevoortia patronus showed significant differences near $\mathrm{p}=0.05$ by both methods, while 4 other species re- mained relatively constant in their niches (Fig. 4b). In Australia, 3 fish species (painted sweetlips, Moses perch and wrasse Pseudolabrus guentheri) showed significant differences in niches across sites, while the other 2 species (yellowfin bream Acanthopagrus australis and rabbitfish Siganus fuscescens) were relatively constant. Overall, the examples of Fig. 4 that included fished sites (USA) and unfished sites (Australia, reserve sites) indicate that average similarities near $80 \%$ may be typical for both estuarine food webs and feeding niches of estuarine fish.

The methods also indicated interesting trends among food webs. The USA site comparisons showed some differentiation across the salinity gradient, with the most marine (salinity $=17$ ) food web at GT differing from the fresher (salinity = 9) upstream MV food web (Fig. 4a). The MV food web showed near $100 \%$ similarity to the freshest (salinity $=6$ ) FP food web (Fig. 4a). The dissimilarities were mostly due to 1 species, Gulf menhaden, which had lower $\mathrm{N}$ isotope values at the most marine station, GT (Figs. 1 \& 2). A 
more phytoplankton-based diet with lower $\mathrm{N}$ isotope values may be indicated at GT, an area with consistently elevated chlorophyll levels (Das et al. 2011). More zooplanktivory with higher $\mathrm{N}$ isotope values may be indicated for menhaden at the 2 other more freshwater stations, MV and FP.

In Moreton Bay, Australia, the aggregate food web in the no-fishing marine reserves had diverged to varying degrees from other local food webs and retained only 60 to $90 \%$ similarity (Fig. 4 a; pairwise comparisons between aggregated reserve [' $R$ '] sites and other sites, including aggregated reserve versus non-reserve ['non'] sites; R NON comparison in Fig. 4). Differences were mostly due to a $1.3 \%$ higher average $\delta^{15} \mathrm{~N}$ value for Moses perch (snapper) in the reserve sites. This species consumes both invertebrates and fish, and was the most piscivorous of the 5 local fish species studied. One possible explanation for the higher $\delta^{15} \mathrm{~N}$ values in the reserve sites is that Moses perch are feeding more heavily on fish that are generally observed to be more abundant at the reserve sites. This hypothesis of increased piscivory will need further field work to better understand the Moses perch trophic shift, but this shift possibly provides a way to monitor divergence of food webs in reserves versus non-reserves.

The Moreton Bay food web that was most different from the aggregate marine reserve food web was the food web at GI (Fig. 4a). This site was also distinguished by the presence of branching coral, a habitat feature not common at other Moreton Bay study sites.

\section{DISCUSSION}

The rescaling approaches of this study represent a distillation and extension of previous isotope methods used to compare fish food webs. The approaches outlined in this and 2 previous studies (Schmidt et al. 2007, Turner et al. 2010) all start with C and N isotope biplots, but differ in how they treat isotope shifts related to baselines and diet strategies of individual groups or species.

The baseline problems were recognized in the first of these studies (Schmidt et al. 2007), for example with eutrophication increasing $\delta^{15} \mathrm{~N}$ values of fish over time. This increase could be erroneously interpreted as a general increase in fish trophic level, and considerable effort has been made to account for these vertical $\delta^{15} \mathrm{~N}$ baseline shifts in food web $\mathrm{CN}$ isotope diagrams (Vander Zanden \& Rasmussen 1999, Post 2002). Baseline shifts can also occur in C isotopes, and a horizontal baseline $\delta^{13} \mathrm{C}$ change of this type is evident in the 2 fish communities of Fig. 1. The community from the more freshwater site (Fig. 1, left food web) had lower $\delta^{13} \mathrm{C}$ values due to lower inputs of seawater bicarbonate at the base of the food web, and this type of $\delta^{13} \mathrm{C}$ baseline change regularly propagates to phytoplankton and then to consumers in estuarine food webs (Fry 2002, Wissel et al. 2005). In summary, both vertical $\delta^{15} \mathrm{~N}$ and horizontal $\delta^{13} \mathrm{C}$ baseline changes can occur in the $\mathrm{CN}$ isotope plots. The circular statistics of Schmidt et al. (2007) did not account explicitly for these baseline shifts that had to be assessed independently to correctly interpret food web change.

To account for baseline shifts, Turner et al. (2010) converted isotope data to Z-scores, and our study follows this same approach, with some rescaling of $Z$ scores to convert values back to units near those of the original study. The intent here is to use $Z$-scores to separate the baseline geochemical changes from changes in fish feeding behaviour, but 2 general caveats can be noted for this use of $Z$-scores.

First, $Z$-score methods make average corrections that apply to all species, rather than more detailed corrections for individual species. The more detailed corrections are desirable (Newsome et al. 2007), but are much more data-intensive and often suffer from their own problems as outlined in our 'Introduction'. $Z$-score methods can be problematic if foods shift isotope values in non-uniform, dynamic ways, as can occur in estuaries and lakes (Cloern et al. 2002, O'Reilly \& Hecky 2002). In such cases, simple meanbased corrections will leave some of the food-related signals in the corrected data where it is then scored as changes in fish behaviour. Two factors usually work together to minimize such problems for fish food webs. Most importantly, the generally high trophic levels and opportunistic feeding habits of fish act to integrate and average many basal food web variations. In addition, including data from multiple fish species helps ensure that average baseline corrections are reasonably representative for the whole community. Thus we focused on studies that included several (5 to 10) species when making comparisons of fish food webs. In contrast, if food webs are composed of a few specialist species, use of $Z$ scores and their underlying average corrections may underestimate the complexities involved in food web comparisons, and lead to erroneous results.

A second caveat about the $Z$-score approach concerns model complexity, and the idea that adding unneeded corrections can introduce artefacts into the analysis. For example, Turner et al. (2010) used Zscores but then added another step of rotating the 
data before making isotope comparisons. This rotation step is usual in Procrustes analysis of fish morphometry (Zelditch et al. 2004), which assumes morphometry is organized tightly around axes that can rotate left or right. However, we observed that food webs were not so fixed in shape and indeed were quite flexible. Food web shapes in $\mathrm{CN}$ isotope space changed when a single species moved or when species exchanged positions; we did not observe all species rotating in a coordinated manner through isotope space. Experimentally rotating our own data to produce minimum differences and best fits of the Procrustes analysis (Zelditch et al. 2004) gave the expected result that rotation will generally disperse and diffuse isotope shifts across all species, while un-rotated data better localized isotope changes to individual species. In sum, we did not rotate data because this rotation step is not widely recognized as a necessary part of baseline adjustments in food web isotope studies, and because rotation can introduce unwanted artefacts into the analysis. Our methods are thus slightly simpler than steps advocated by Turner et al. (2010), generally have fewer assumptions and are probably more appropriate for food webs that, according to our observations, do not have fixed morphometry or shape.

Our Z-score method involves dividing by standard deviations, and this provides a uniform scale for understanding and comparing food webs. Several previous studies have used isotopes to study changes in food webs (Bearhop et al. 2004, Layman et al. 2007, 2012), but have not used a uniform scale for comparisons. This lack of a uniform scale makes comparative evaluation of food webs difficult (Hoeinghaus \& Zeug 2008), and our study shows simple algebraic steps for the re-scaling process (Supplements 1 \& 2), along with some initial applications. Details of these novel rescaling calculations for the modified $Z$-scores are given in Supplements $1 \& 2$. Rescaled averages were used in the rather simple Euclidean distance framework of this study, but rescaled individual-level data also can be used in multivariate programs to detect food web change (Supplement 3).

Our survey of published food webs included diverse examples including ponds with an invasive species, the deep sea, dredged rivers and estuaries from the USA, Australia and Africa (Fig. 3). The survey of food webs was useful for establishing a way to estimate food web differences, but also showed other interesting features. First, the food webs with the strongest differences were those identified as disturbed by human-mediated species invasion $(20 \%$ similar) and by river dredging (48\% similar; Fig. 3b).
Second, while invasive species and dredging effects were strongest, nearly as-strong differences were observed in 2 studies of mid-water deep-sea fish communities in the Mediterranean (64\% similar) and Tasman Seas (72\% similar; Fig. 3b). These deep-sea studies respectively documented seasonal differences and spatial differences, with both showing that these communities are shifting fairly strongly and presumably naturally along time and space axes. In contrast, the estuarine food webs in the USA, Australia and Africa showed much greater similarities of respectively 87,87 and $96 \%$. We do not know the causes of these differences at this time, but it is possible that food limitation is important in the overall degree of similarity in food webs, with deep-sea food webs diverging because of low food availability (Watling et al. 2013) but estuarine food webs showing stronger similarity because of greater in situ primary productivity and food availability.

A second axis of differentiation in estuarine food webs may be related to habitat structure, with relatively high fish diversity at the GI site that had branching coral (J. Davis pers. obs.). Carbon isotope variability associated with mean isotope values were lowest at this site among all Australian estuarine sites studied, and may reflect higher residency and more structured food webs at GI. Further studies of coral reef sites are needed to extend these initial observations and test possible habitat controls of food web structure and function.

Our survey of fish food web studies generally found that samples had not been collected with comparisons of whole food webs in mind. Our work in Moreton Bay involved spear-fishing a few (3 to 5) individuals per species at multiple sites, in contrast to a previous estuarine study that recommended typical monitoring numbers of 30 to 45 fish per species replicate (Fry et al. 2008). These higher numbers are in line with estimates for lake fish that $>30$ individuals may be needed for statistical power when using isotopes to study a niche of 1 fish species (Syväranta et al. 2013). Also in this survey work, we did not encounter studies that explicitly included replicate whole food webs, for example collecting the same species assemblage in 3 nearby areas for replicate food webs. This could be expanded across seasons to also address temporal replication. Our initial studies in USA and Australian estuaries (Fig. 4) generally had low numbers of individuals and low replication across time and are presented mostly to show the potential of the rescaling comparative approach. Increased replication is desirable to make more robust comparisons of food webs. 
Besides increased replication, choice of species may also be important for comparing food webs. Generally, more mobile species will have higher variability estimates and greater final estimated trophic similarity across sites and seasons. Conversely, betterdefined trophic niches for individual species that are resident should provide higher-resolution opportunities for distinguishing food web differences. Future research might also improve the isotope descriptions of food webs by including more species, and especially most of the abundant species. It is possible that food webs seem dissimilar because many of the important species are lacking, i.e. food webs studied thus far are only partial representations of field conditions with usually less than $50 \%$ of abundant species represented in the isotope sampling. The isotope food web approach elaborated here might work best in estuarine studies with 20 to $50 \mathrm{~cm}$ sized fish that (1) are large enough to consume a wide variety of prey and have fairly stable average diets, (2) show some regular habitat associations with e.g. water masses or benthic structures and (3) are small enough to remain fairly local and resident. While these recommendations arise from our initial work with species-based fish food webs, we note that there are many potential related food web comparisons that could focus on e.g. fish size classes instead of species (Jennings et al. 2002), invertebrate communities or mixed invertebrate/fish communities.

Acknowledgements. We thank Michael Arthur, Kylie Pitt and 3 anonymous reviewers for helpful comments during preparation of this manuscript.

\section{LITERATURE CITED}

Abrantes KG, Barnett A, Marwick TR, Bouillon S (2013) Importance of terrestrial subsidies for estuarine food webs in contrasting East African catchments. Ecosphere 4:art14

Bearhop S, Adams CE, Waldron S, Fuller RA, MacLeod H (2004) Determining trophic niche width: a novel approach using stable isotope analysis. J Anim Ecol 73:1007-1012

Britton JR, Davies GD, Harrod C (2010) Trophic interactions and consequent impacts of the invasive fish Pseudorasbora parva in a native aquatic foodweb: a field investigation in the UK. Biol Invasions 12:1533-1542

Cloern JE, Canuel EA, Harris D (2002) Stable carbon and nitrogen isotope composition of aquatic and terrestrial plants of the San Francisco Bay estuarine system. Limnol Oceanogr 47:713-729

$>$ Das A, Justic D, Swenson E, Turner RE, Inoue M, Park D (2011) Coastal land loss and hypoxia: the 'outwelling' hypothesis revisited. Environ Res Lett 6:025001

$>$ Davis JP, Pitt KA, Fry B, Olds AD, Connolly RM (2014) Seascape-scale trophic links for fish on inshore coral reefs. Coral Reefs 33:897-907
Flynn AJ, Kloser RJ (2012) Cross-basin heterogeneity in lanternfish (family Myctophidae) assemblages and isotopic niches $\left(\delta^{13} \mathrm{C}\right.$ and $\left.\delta^{15} \mathrm{~N}\right)$ in the southern Tasman Sea abyssal basin. Deep-Sea Res I 69:113-127

> Freedman JA, Carline RF, Stauffer JR Jr (2013) Gravel dredging alters diversity and structure of riverine fish assemblages. Freshw Biol 58:261-274

> Fry B (2002) Conservative mixing of stable isotopes across estuarine salinity gradients: a conceptual framework for monitoring watershed influences on downstream fisheries production. Estuaries 25:264-271

Fry B (2007) Coupled N, C, and S isotope measurements using a dual column GC system. Rapid Commun Mass Spectrom 21:750-756

Fry B (2013a) Alternative approaches for solving underdetermined isotope mixing problems. Mar Ecol Prog Ser 472:1-13

> Fry B (2013b) Using stable CNS isotopes to evaluate estuarine fisheries condition and health. Isotopes Environ Health Stud 49:295-304

> Fry B, Chumchal MM (2011) Sulfur stable isotope indicators of residency in estuarine fish. Limnol Oceanogr 56: 1563-1576

Fry B, Chumchal MM (2012) Hg bioaccumulation in estuarine food webs. Ecol Appl 22:606-623

Fry B, Cieri M, Hughes J, Tobias C, Deegan LA, Peterson B (2008) Stable isotope monitoring of benthic-planktonic coupling using salt marsh fish. Mar Ecol Prog Ser 369: 193-204

> Hoeinghaus DJ, Zeug SC (2008) Can stable isotope ratios provide for community-wide measures of trophic structure? Comment. Ecology 89:2353-2357

Jennings S, Pinnegar JK, Polunin NVC, Warr KJ (2002) Linking size-based and trophic analyses of benthic community structure. Mar Ecol Prog Ser 226:77-85

Layman CA, Arrington DA, Montana CG, Post DM (2007) Can stable isotope ratios provide quantitative measures of trophic diversity within food webs? Ecology 88:42-48

Layman CA, Araujo MS, Boucek R, Hammerschlag-Peyer CM and others (2012) Applying stable isotopes to examine food-web structure: an overview of analytical tools. Biol Rev Camb Philos Soc 87:545-562

$>$ Mallela J, Harrod C (2008) $\delta^{13} \mathrm{C}$ and $\delta^{15} \mathrm{~N}$ reveal significant differences in the coastal foodwebs of the seas surrounding Trinidad and Tobago. Mar Ecol Prog Ser 368:41-51

- McCutchan JH, Lewis WM, Kendall C, McGrath CC (2003) Variation in trophic shift for stable isotope ratios of carbon, nitrogen, and sulfur. Oikos 102:378-390

> Newsome SD, del Rio CM, Bearhop S, Phillips DL (2007) A niche for isotopic ecology. Front Ecol Environ 5:429-436

O'Reilly CM, Hecky RE (2002) Interpreting stable isotopes in food webs: recognizing the role of time averaging at different trophic levels. Limnol Oceanogr 47:306-309

Osada R, Funkhouser T, Chazelle B, Dobkin D (2002) Shape distributions. Trans Graphics 21: 807-832

- Papiol V, Cartes JE, Fanelli E, Rumolo P (2013) Food web structure and seasonality of slope megafauna in the NW Mediterranean elucidated by stable isotopes: relationship with available food sources. J Sea Res 77:53-69

> Phillips DL (2012) Converting isotope values to diet composition: the use of mixing models. J Mammal 93:342-352

Post DM (2002) Using stable isotopes to estimate trophic position: models, methods, and assumptions. Ecology 83: 703-718 
Schmidt SN, Olden JD, Solomon T, Vander Zanden MJ (2007) Quantitative approaches to the analysis of stable isotope food web data. Ecology 88:2793-2802

Syväranta J, Lensu A, Marjomaki TJ, Oksanen S, Jones RI (2013) An empirical evaluation of the utility of convex hull and standard ellipse areas for assessing population niche widths from stable isotope data. PLoS ONE 8:e56094

$>$ Turner TF, Collyer ML, Krabbenhoft TJ (2010) A general hypothesis-testing framework for stable isotope ratios in ecological studies. Ecology 91:2227-2233

Vander Zanden MJ, Rasmussen JB (1999) Primary consumer $\delta^{13} \mathrm{C}$ and $\delta^{15} \mathrm{~N}$ and the trophic position of aquatic consumers. Ecology 80:1395-1404

Editorial responsibility: Janet Ley,

St. Petersburg, Florida, USA
Vander Zanden MJ, Vadeboncoeur Y, Chandra S (2011) Fish reliance on littoral-benthic resources and the distribution of primary production in lakes. Ecosystems 14: 894-903

Watling L, Guinotte J, Clark MR, Smith CR (2013) A proposed biogeography of the deep ocean floor. Prog Oceanogr 111:91-112

Wissel B, Gace A, Fry B (2005) Tracing river influences on phytoplankton dynamics in two Louisiana estuaries. Ecology 86:2751-2762

Zelditch ML, Swiderski DL, Sheets HD, Fink WL (2004) Geometric morphometrics for biologists: a primer. Academic Press, Burlington, MA

Submitted: October 17, 2014; Accepted: March 23, 2015 Proofs received from author(s): May 4, 2015 